\title{
A pandemia de covid-19 e o pandemônio do (tele) trabalho: reflexões a partir da experiência das/os assistentes sociais na área da saúde
}

\section{The covid-19 pandemic and the pandemonium of telework: reflections based on the action of social assistants in the health field}

\author{
Keli Regina Dal Prá* \\ Débora Martini* \\ Suzane Pereira da Cruz ${ }^{* \star}$
}

\begin{abstract}
Resumo: A pandemia provocada pelo coronavírus SARS-CoV-2 impôs a reorganização do trabalho em diversos segmentos e setores econômicos, no âmbito público e privado. Sendo um vírus de alto grau de contaminação, as autoridades sanitárias indicaram como principal medida para contenção do contágio o isolamento social, o que levou à criação de estratégias de teletrabalho, inclusive na área da saúde. A partir desse contexto, o artigo objetiva refletir sobre a organização do teletrabalho das/os Assistentes Sociais nos serviços de Atenção Primária em Saúde (APS) no contexto da pandemia de COVID-19 em uma capital do Sul do Brasil. Em termos metodológicos, realizouse uma revisão da literatura e uma pesquisa documental em normativas dos órgãos regulamentadores da profissão da área de Serviço Social e da instituição empregadora das/os profissionais acerca do teletrabalho. Os resultados indicaram haver dificuldade na definição conceitual sobre o teletrabalho nos âmbitos teórico, normativo e na área do Serviço Social, e que a realidade desta forma de atuação para a Profissão na APS se intensificou com a pandemia, aprofundando questões relacionadas à precarização das condições de trabalho
\end{abstract}

\footnotetext{
*Doutora e Mestre em Serviço Social pela Pontifícia Universidade Católica do Rio Grande do Sul (PUCRS). Assistente Social. Docente do Departamento de Serviço Social da Universidade Federal de Santa Catarina (UFSC) nos Cursos de Graduação e Pós-Graduação em Serviço Social e no Programa de Residência Multiprofissional em Saúde da Família. E-mail: keli. regina@ufsc.br.

${ }^{* *}$ Mestre em Serviço Social pelo Programa de Pós-Graduação em Serviço Social da Universidade Federal de Santa Catarina (UFSC) e Especialista em Saúde da Família pelo Programa de Residência Multiprofissional em Saúde da Família da UFSC. Assistente Social. Tutora dos Programas de Residência Multiprofissional em Saúde da Família da Escola de Saúde Pública (ESP) de Florianópolis. E-mail: deboramartinisso@gmail.com.

*** Especialista em Saúde da Família pelo Programa de Residência Multiprofissional em Saúde da Família da Universidade Federal de Santa Catarina (UFSC). Assistente Social. E-mail: suzanepereiradacruz@gmail.com.
} 
e do acesso institucional às Tecnologias da Informação e Comunicação (TIC) para o atendimento da população.

Palavras-chave: Serviço Social. Atenção Primária em Saúde. Teletrabalho. Pandemia de COVID-19.

\begin{abstract}
The pandemic of the new coronavirus (COVID-19) imposed a reorganization of labor in various public and private economic sectors. Because the virus is highly contagious, sanitary authorities indicate social isolation as the main measure for limiting its spread, leading to the insertion of strategies of telework, including in the field of healthcare. In this context, this article reflects on the organization of telework among social assistants engaged in services of Brazil's federal Primary Healthcare program during the Covid-19 pandemic in a capital in southern Brazil. The methodology involved a review of the literature and research of documents concerning telework produced by agencies that regulate the profession of social service and by an institution that employs these professionals. The results indicate a difficulty in establishing a conceptual definition about telework in the theoretical and normative realms and in the field of social service, and that the reality of telework for the profession in the Primary Healthcare program intensified during the pandemic. This raises profound questions about the precarity of working conditions and institutional access to information and communication technologies needed to serve the population.
\end{abstract}

Keywords: Social Service. Primary Healthcare program. Telework. COVID-19 Pandemic.

\title{
Introdução
}

A situação emergencial imposta em razão da pandemia causada pelo coronavírus SARSCoV-2 (COVID-19), que se instalou na realidade brasileira em fevereiro de 2020, expôs a questão das condições de trabalho diante do risco de contaminação em muitas atividades profissionais. Os espaços sócio-ocupacionais foram afetados pela pandemia e foi preciso reorganizar suas estruturas, a fim de garantir que as/os profissionais seguissem trabalhando com o mínimo de segurança. Esse foi o caso dos serviços de saúde, em todos os seus níveis de atenção, mas especialmente naqueles oferecidos pelo Sistema Único de Saúde (SUS), pois o sistema público brasileiro de saúde e suas/seus profissionais foram, e ainda seguem sendo, fundamentais no atendimento às pessoas acometidas pela COVID-19.

Os setores público e privado passaram a prever diferentes possibilidades de trabalho diante do risco de contágio das/os trabalhadoras/es pelo novo coronavírus e, por isso, muitas/ os profissionais, que em suas lotações de trabalho não se encontravam na linha de frente do 
atendimento direto à população, passaram a vivenciar jornadas de trabalho mistas, realizando parte do trabalho presencial e parte na modalidade remota.

Nesse contexto, estão inseridas/os as/os Assistentes Sociais que trabalham em diferentes serviços sociais das políticas públicas, particularmente na saúde e assistência social. Para essas/ es profissionais, bastante atingidas/os pela pandemia, o teletrabalho passou a ser uma realidade, já que as demandas de atendimento por parte da população cresceram significativamente com o agravamento das desigualdades sociais, levando, inclusive, ao advento de auxílios emergenciais disponibilizados pelos governos federal e municipal.

O tema do teletrabalho não é objeto de normativas específicas elaboradas pelos órgãos regulamentadores da profissão, como o Conselho Federal e os Conselhos Regionais de Serviço Social (CFESS/CRESS), além de ser um tema que carece de aprofundamento teórico no âmbito do Serviço Social, apesar de o trabalho profissional em espaços como o sociojurídico oferecer indicativos da relevância e necessidade dessa discussão na profissão e por suas/seus profissionais.

Por essas questões, neste artigo pretende-se refletir acerca da organização do teletrabalho das/os Assistentes Sociais nos serviços de Atenção Primária em Saúde (APS) no contexto da pandemia de COVID-19 em uma capital do Sul do Brasil. As reflexões aqui apresentadas são embasadas metodologicamente na revisão de literatura sobre o tema 'teletrabalho', abrangendo questões conceituais, sua relação com o Serviço Social e em pesquisa documental envolvendo os principais documentos orientadores produzidos pelo conjunto CFESS/CRESS e pela instituição empregadora das/os profissionais, nesse caso, a Prefeitura Municipal de Florianópolis (PMF), quando foi realizada a regulamentação da modalidade de teletrabalho às/aos trabalhadoras/es municipais diante do contexto citado.

O texto parte de reflexões acerca do conceito de teletrabalho, trabalho remoto e home office, termos que, muitas vezes, são tratados como sinônimos. Na sequência são abordadas as expressões dessa modalidade de trabalho no cotidiano das/os Assistentes Sociais atuantes na área da saúde, especificamente na APS, no Núcleo Ampliado em Saúde da Família e Atenção Básica (NASF-AB), tendo como base a experiência no município de Florianópolis/SC.

\section{Teletrabalho, trabalho remoto e home office}

Para refletir sobre a organização do trabalho desenvolvido pelas/os Assistentes Sociais na área da saúde no contexto da pandemia de COVID-19, faz-se necessário diferenciar alguns termos, tais como teletrabalho, trabalho remoto e home office, pois não há uma definição consensual acerca deles, tanto no âmbito legal/normativo como na produção teórica (FILHO; BRASIL, 2019). Existem algumas divergências semânticas e conceituais sobre o teletrabalho, ou seja, há diferentes nomenclaturas se referindo às mesmas práticas, bem como situações bastante divergentes referidas pelos mesmos termos (ROCHA; AMADOR, 2018).

Para fins deste artigo, a primeira busca pela definição dos termos teletrabalho, trabalho remoto e home office ocorreu na Consolidação das Leis do Trabalho (CLT ${ }^{1}$ ), no art. 75-B, que define o teletrabalho como: “[...] a prestação de serviços preponderantemente fora das dependências do empregador, com a utilização de tecnologias de informação e de comunicação que, por sua natureza, não se constituam como trabalho externo." (BRASIL, 1943, n.p.). A realização majoritária

${ }^{1}$ O teletrabalho passou a ter regulamentação específica na CLT a partir da Lei n. 13.467, de 13 de julho 2017 (BRASIL, 2017). 
da prestação de serviços fora das dependências do empregador não exclui o comparecimento do trabalhador nessas dependências para realizar atividades específicas.

Outra questão importante indicada no art. 75-C é que "a prestação de serviços na modalidade de teletrabalho deverá constar expressamente do contrato individual de trabalho, que especificará as atividades que serão realizadas pelo empregado" (BRASIL, 1943, n.p.). Além do que a "responsabilidade pela aquisição, manutenção ou fornecimento dos equipamentos tecnológicos e da infraestrutura necessária e adequada à prestação do trabalho remoto, bem como ao reembolso de despesas arcadas pelo empregado, serão previstas em contrato escrito", conforme prevê o art. 75-D (BRASIL, 1943, n.p.). Observa-se que na redação desse último artigo o termo utilizado não é teletrabalho, mas trabalho remoto, indicando que os dois termos seriam sinônimos.

Já a Organização Internacional do Trabalho (OIT), na Convenção n. 177, de 4 de junho de 1996, apesar de usar a expressão "trabajo a domicilio", define teletrabalho como aquele realizado

[...] (i) en su domicilio o en otros locales que escoja, distintos de los locales de trabajo del empleador; (ii) a cambio de una remuneración; (iii) con el fin de elaborar un producto o prestar un servicio conforme a las especificaciones del empleador, independientemente de quién proporcione el equipo, los materiales $u$ otros elementos utilizados para ello, a menos que esa persona tenga el grado de autonomía y de independencia económica necesario para ser considerada como trabajador independiente en virtud de la legislación nacional o de decisiones judiciales; [...]. (OIT, 1996, n.p.).

A definição da OIT propõe indicações mínimas para a caracterização do teletrabalho, a fim de contemplar tal conceito nas legislações nacionais, que determinarão as particularidades de cada país signatário. No entanto, a Convenção deixa claro que teletrabalho é a "realização do labor em local distinto do estabelecimento empresarial, mediante remuneração e com subordinação jurídica" (FILHO; BRASIL, 2019, p. 120).

Segundo Filho e Brasil (2019, p. 113), o teletrabalho é uma forma de desempenhar as atividades laborativas que, apesar da recente ampliação em razão do contexto pandêmico, em meio aos diferentes ambientes de trabalho, "especialmente diante de fatores como a popularização da internet, ampliação do setor de prestação de serviços e amplo desenvolvimento dos recursos de tecnologia da informação, tem sua origem controversa". Por esse motivo, importa destacar outras expressões ligadas ao teletrabalho:

- Trabalho em domicílio - aquele desenvolvido na casa do empregado/trabalhador ou em oficina de família, geralmente ligado a uma relação de produção material, remunerado por um empregador. Em uma concepção mais ampla, dada pelo entendimento jurídico, seria aquele trabalho realizado fora da empresa, na residência do empregado, ou em qualquer outro local escolhido por ele (FILHO; BRASIL, 2019; ROCHA; AMADOR, 2018).

- Trabalho externo - aquele desenvolvido fora do estabelecimento do empregador, longe de sua fiscalização e controle. Nesta modalidade os trabalhadores necessariamente saem da empresa para realizar seus serviços, como ocorre, por exemplo, com representantes comerciais e uma gama de outras atividades profissionais (FILHO; BRASIL, 2019; ROCHA; AMADOR, 2018).

- Trabalho a distância - aquele realizado pelo empregado sem a vigilância pessoal e direta do empregador, semelhante ao trabalho externo (FILHO; BRASIL, 2019; ROCHA; AMADOR, 2018).

- Trabalho remoto - aquele menos vinculado à produção industrial e desenvolvido necessariamente com o uso de Tecnologias de Informação e Comunicação (TIC) (ROCHA; AMADOR, 2018). 
- Trabalho em home office - aquele onde os trabalhadores desenvolvem "a maior parte do trabalho na própria residência; fora, portanto, do escritório da empresa ou de qualquer outro tipo de ambiente físico profissional" (BARROS; SILVA, 2010, p. 73). A utilização das TIC enquadra o trabalho em home office como modalidade de teletrabalho (FILHO; BRASIL, 2019).

A partir dessas conceituações, é importante destacar que o teletrabalho apresenta algumas características que o individualizam: a distância do local de trabalho definido pelo empregador; a descentralização das atividades desenvolvidas pelo estabelecimento empresarial; e o uso de TIC. Ou seja, o trabalhador desempenha, em outro local, as mesmas funções que realizaria na empresa, podendo ter sua jornada de trabalho fiscalizada. A fiscalização do teletrabalho é prevista na legislação brasileira pelos meios telemáticos e informatizados, já que não há distinção do trabalho realizado na sede da empresa com aquele realizado no domicílio do empregado e/ou realizado a distância, desde que haja caracterização dos pressupostos da relação de emprego (BRASIL, 2011).

A breve conceituação apresentada sobre alguns dos termos relacionados ao teletrabalho tem o objetivo de pensar a organização do trabalho das/os Assistentes Sociais na área da saúde, no setor público, realizada por meio do uso das TIC. Destaca-se que, apesar das discussões conceituais se referirem especialmente ao trabalho celetista ou no âmbito privado, muitas das características desses são tomadas pelo setor público, que passou a estruturar e intensificar o teletrabalho, inicialmente como consequência das medidas de distanciamento social com a finalidade de conter a disseminação da COVID-19.

O teletrabalho vem se associando a mudanças que estão sendo introduzidas no âmbito da administração dos processos de trabalho. São processos pensados e desenvolvidos nos últimos tempos, "[...] caracterizados pela visão produtivista, na qual o trabalho técnico é mensurado por prazos e metas, com foco em resultados, pela redução de custos, pela conformação de um(a) profissional polivalente" e que foram intensificados nesse momento pandêmico (TEJADAS; JUNQUEIRA, 2021, p. 109).

Um exemplo de como o setor público federal vem adotando o teletrabalho é a Instrução Normativa n. 65, de 30 de julho de 2020 que orienta e estabelece critérios e procedimentos a serem considerados pelos órgãos e entidades integrantes do Sistema de Pessoal Civil da Administração Federal (BRASIL, 2020). No referido documento, o termo teletrabalho é definido como:

[...] modalidade de trabalho em que o cumprimento da jornada regular pelo participante pode ser realizado fora das dependências físicas do órgão, em regime de execução parcial ou integral, de forma remota e com a utilização de recursos tecnológicos, para a execução de atividades que sejam passíveis de controle e que possuam metas, prazos e entregas previamente definidos e, ainda, que não configurem trabalho externo, dispensado do controle de frequência [...]. (BRASIL, 2020, n.p., grifo nosso).

No trecho supracitado, percebe-se o uso do termo teletrabalho como sinônimo de trabalho remoto e há a indicação da necessidade dessa modalidade de trabalho ser fiscalizada ou controlada a partir de resultados previamente definidos. Nesse sentido, há duas indicações de quando o teletrabalho não pode ser realizado no âmbito público federal: 1) em atividades que exijam a presença física da/o servidor/a na unidade ou em atividades desenvolvidas por meio de trabalho externo; e 2) quando a adoção do teletrabalho reduzir a capacidade de atendimento ao público interno e externo (BRASIL, 2020). 
No entanto, o que mais chama a atenção são os objetivos do programa de gestão proposto pelo Governo Federal que, em nenhum momento, menciona a adoção de medidas de teletrabalho como possibilidade de resguardar a segurança, pelo menos de significativa parcela das/os trabalhadoras/es, em função do contágio da COVID-19. Dentre os oito objetivos descritos, destaca-se o segundo deles, que é "II - contribuir com a redução de custos no poder público", aliado ao estabelecimento da "cultura de governo digital" e da "cultura orientada a resultados, com foco no incremento da eficiência e da efetividade dos serviços prestados à sociedade” (BRASIL, 2020, n.p.).

A centralidade da adoção do teletrabalho no serviço público federal ocorre prioritariamente visando reduzir custos. Essa orientação é explícita no art. 13, que aponta o dever da/o servidor/a em teletrabalho de "[...] manter a infraestrutura necessária para o exercício de suas atribuições, inclusive aquelas relacionadas à segurança da informação [...]” (BRASIL, 2020, n.p.). Além disso, o art. 23 define que

[...] caberá ao participante providenciar as estruturas física e tecnológica necessárias, mediante a utilização de equipamentos e mobiliários adequados e ergonômicos, assumindo, inclusive, os custos referentes à conexão à internet, à energia elétrica e ao telefone, entre outras despesas decorrentes do exercício de suas atribuições. (BRASIL, 2020, n.p.).

Na conjuntura de um Governo Federal orientado por preceitos ultraliberais e por políticas de austeridade fiscal, o incentivo ao teletrabalho significa transferir às/aos trabalhadoras/ es os custos dessas atividades. A economia estatal com o teletrabalho está em deixar de pagar, por exemplo, auxílio-transporte, vantagens por prestação de serviços extraordinários, compensações em bancos de horas por serviços prestados para além do horário de trabalho estipulado ao/à servidor/a, e também envolve a expressiva redução de gastos com água, energia elétrica, internet, material de consumo, manutenção de equipamentos, dentre outros.

Destaca-se que, além dos custos financeiros do teletrabalho assumidos pelas/os trabalhadoras/es dos setores privado e público, há aspectos de um custo social e de saúde, como apontam Bridi et al. (2020) em pesquisa que identificou: o aumento de horas diárias trabalhadas e de dias trabalhados semanalmente; o aceleramento do ritmo de trabalho na modalidade remota, quando em comparação ao trabalho presencial; e o aumento de metas de produtividade no período da pandemia.

Também foram apontados pelas/os participantes do estudo como dificuldades do trabalho remoto: a falta de contato com colegas de trabalho; mais interrupções; e dificuldade em separar a vida familiar da vida profissional. A dificuldade de separar o tempo de trabalho e o tempo de não trabalho, aliada às más condições ergonômicas e à pressão por resultados, são aspectos que acabam se refletindo na saúde física e mental e na sociabilidade das/os trabalhadoras/es, influenciando também a qualidade do trabalho realizado.

Pouco se tem refletido sobre o aspecto da qualidade dos serviços prestados à sociedade a partir do teletrabalho (BRIDI et al., 2020) e também pouco se tem aprofundado sobre as questões relacionadas à divisão sexual do trabalho, exacerbada no contexto pandêmico, uma vez que, com o fechamento presencial de serviços relacionados à educação, por exemplo, os cuidados com os filhos passaram a sobrecarregar ainda mais as mulheres. Segundo Bridi et al. (2020, n.p.), as respostas das mulheres ao estudo destacaram os “termos 'casa', 'filho', 'cuidado' e 'criança”. Já no caso dos homens, eles destacaram os “termos 'tempo', 'contrato', 'pandemia' e 'casa', sendo que o termo 'casa' se associa à questão de gestão do tempo de trabalho e não ao cuidado com filhos e 
o trabalho doméstico", evidenciando uma diferença significativa na forma como o teletrabalho tem sido realizado por homens e mulheres.

Esse contexto traz questões importantes para o Serviço Social, uma vez que a profissão constitui-se majoritariamente por mulheres que trabalham em serviços sociais públicos e que enfrentam condições semelhantes às anteriormente mencionadas para desenvolverem suas atividades em teletrabalho.

\section{Serviço social e teletrabalho: aspectos da atuação profissional na área da saúde na pandemia de COVID-19 em Florianópolis}

A pandemia de COVID-19 praticamente impôs, para uma parte das/os Assistentes Sociais, a realidade do teletrabalho, mesmo essa modalidade não sendo regulamentada pelo conjunto CFESS/CRESS. Essa realidade gerou questionamentos das/os profissionais inseridas/os em vários serviços das políticas sociais, especialmente nos casos das áreas de saúde e assistência social, mobilizando o CFESS (2020) a divulgar um documento orientador específico sobre o tema do teletrabalho. Nesse documento, o Conselho Federal pontua assertivamente que, em razão da pandemia de COVID-19, acelerou-se o processo de uso das TIC no trabalho das/os Assistentes Sociais, algo já vivenciado em maior ou menor intensidade por profissionais inseridas/os em diferentes espaços sócio-ocupacionais².

Tendo em vista a necessidade de contribuir com a produção do conhecimento sobre o trabalho das/os Assistentes Sociais no âmbito das políticas sociais no período pandêmico, registram-se aqui aspectos da realidade desse trabalho mediado pelas TIC e pelo teletrabalho na APS, especificamente no NASF-AB ${ }^{3}$, no município de Florianópolis/SC.

Antes de adentrar especificamente no uso das TIC, destaca-se que, de modo geral, as ações profissionais desenvolvidas no NASF-AB possuem como público-alvo as equipes de referência apoiadas e, diretamente, os usuários do SUS. Essas ações são realizadas considerando duas dimensões: a clínico-assistencial e a técnico-pedagógica. A primeira incide sobre ações diretas com os usuários e a segunda produz ação de apoio educativo com e para as equipes de saúde. Em se tratando da estrutura, essas ações devem ser divididas em: compartilhadas no Centro de Saúde, compartilhadas no território e ações específicas dos profissionais do NASF-AB (MARTINI; DAL PRÁ, 2018).

Dito isso, uma retrospectiva da inserção do Serviço Social na APS demonstra o uso das TIC desde antes da pandemia de COVID-19, quando da inserção das/os profissionais no Núcleo de Apoio à Saúde da Família (NASF), em 2008, momento em que a comunicação entre as equipes de Saúde da Família (eSF) e demais profissionais já era realizada por meio de aparelhos telefônicos e aplicativos de mensagens, como o Whatsapp ${ }^{\circledR}$.

Iniciativas pontuais de uso de ferramentas, como e-mails, planilhas do Microsoft Excel ${ }^{\circledast}$, Google Drive ${ }^{\circledR}$ e Google Maps ${ }^{\circledR}$ para comunicação entre profissionais, monitoramento e avaliação das ações de profissionais do NASF-AB e vigilância em saúde já ocorrem desde 2013 (SOUZA; MARTINI, 2014), tendo sido essas ferramentas validadas como instrumentos de trabalho por meio da publicação da Carteira de Serviços da Atenção Primária de Florianópolis. No ano de 2016, porém,

\footnotetext{
${ }^{2}$ Exemplo é a atuação profissional no espaço sociojurídico (FÁVERO, 2020; TEJADAS; JUNQUEIRA, 2021).

${ }^{3}$ Devido aos limites do texto, não será detalhada a atuação da/o Assistente Social no NASF-AB, desse modo, sugere-se a leitura do artigo de Martini e Dal Prá (2018), intitulado A inserção do assistente social na atenção primária à saúde.
} 
com a publicação da Política Municipal de Atenção Primária em Saúde (PMAPS) do município, o uso das TIC foi oficializado nos serviços de saúde e ampliado para a APS (FLORIANÓPOLIS, 2016).

No caso das/dos Assistentes Sociais, por serem parte do NASF-AB e ofertarem apoio para diversas eSF, a PMAPS estabeleceu que elas/es deveriam ser acionadas/os pelas eSF por meio dos pontos de contato preestabelecidos para o apoio técnico-pedagógico. Esses pontos de contato podem ser tanto presenciais, quanto a distância, sendo que, para isso, devem disponibilizar um contato eletrônico e acompanhar regularmente a planilha online de casos compartilhados (FLORIANÓPOLIS, 2014).

A planilha de casos compartilhados é uma ferramenta criada em 2013 inicialmente por uma das equipes de NASF-AB, com a finalidade de auxiliar nos matriciamentos com as eSF, sendo uma forma de acompanhamento das situações matriciadas e encaminhadas para atendimento da equipe do NASF-AB. Inicialmente chamada de "lista de gerenciamento dos casos compartilhados entre NASF-AB e eSF apoiada", a planilha foi criada com a finalidade de desenvolver a gestão conjunta do cuidado na APS. As listas foram organizadas de forma separada por eSF vinculada, com foco usuário-centrado, e disponibilizadas a todas/os as/os profissionais das eSF assistidas. Desse modo, foi possível registrar as ações realizadas de maneira sintética, garantindo o sigilo profissional, uma vez que as informações provenientes dos prontuários não foram utilizadas (SOUZA; MARTINI, 2014).

Utilizando a planilha era possível acompanhar: as filas de espera para cada categoria profissional, por meio da data de encaminhamento e/ou matriciamento da situação e da data do primeiro atendimento; o status de acompanhamento da situação (se estava aguardando atendimento, se estava em atendimento ou em alta); e a/o profissional para a/o qual a situação foi encaminhada, entre outras informações. No ano de 2015, a planilha foi disponibilizada para a coordenação dos NASF-AB, que propôs algumas modificações e expandiu sua utilização para todo o município, tornando-a uma ferramenta utilizada pelos profissionais do NASF-AB e das eSF para gerenciamento das situações matriciadas/encaminhadas.

A planilha era uma das TIC incentivadas pela PMAPS, combinada com as listas de pacientes, o registro em prontuário eletrônico e a comunicação eletrônica por e-mail ou outros aplicativos de comunicação, como o Whatsapp ${ }^{\circledR}$. Cabe destacar que, inicialmente, essas ferramentas eram utilizadas apenas entre profissionais de saúde da APS e envolviam seus recursos próprios (como o aparelho celular), porém, com o passar do tempo, outros níveis de atenção foram incluídos no uso de TIC. A ampliação do trabalho mediado pelas TIC possibilitou discussões de casos clínicos, cuidado compartilhado e orientações a distância, sendo a principal ferramenta o uso do e-mail para apoio matricial. Atualmente, o município conta com pelo menos 36 fluxos de apoio matricial que utilizam o e-mail e os grupos de Whatsapp ${ }^{\circledR}$ como principal forma de comunicação.

Com o passar dos anos e com o aprimoramento do uso de TIC na APS, outras ferramentas foram incluídas e seu uso passou a envolver também usuárias/os dos serviços de saúde, possibilitando sua comunicação com a eSF por meio de ferramentas de mensagens, e-mails, entre outros recursos.

Em 2020, em razão da pandemia de COVID-19, em todas as eSF e Centros de Saúde da APS, para algumas especialidades de média complexidade e profissionais do NASF-AB, houve incentivo à utilização das TIC para a realização do teletrabalho, incluindo o caso das/os Assistentes Sociais. Mesmo que a realidade do teletrabalho não seja imposta igualmente a todas/os as/os profissionais, uma vez que outras possibilidades de organização do trabalho foram pensadas para reduzir ou evitar o contágio do novo coronavírus, o uso das TIC repercute nos processos de trabalho em que 
se insere a/o Assistente Social, "na relação com outras profissões e trabalhadores/as, na relação com usuários/as e nas condições éticas e técnicas de trabalho” (CFESS, 2020, p. 2).

No caso do trabalho profissional na área da saúde em Florianópolis/sC, o início do período pandêmico provocou inúmeras, rápidas e intensas mudanças na organização dos serviços. De modo geral, as/os profissionais de todas as categorias que não atuavam na linha de frente atendendo pessoas com síndrome respiratória aguda grave, na APS e no NASF-AB, passaram a colaborar nos serviços em funcionamento, nos esforços de combate à pandemia e nas atividades específicas de cada categoria, priorizando atendimentos de urgência, não presenciais, ações de cuidado às/aos trabalhadora/es dos Centros de Saúde, atividades organizacionais e apoio matricial a distância (FLORIANÓPOLIS, 2020).

As/os profissionais de saúde que atendiam aos critérios de teletrabalho estabelecidos pela PMF (relacionados a comorbidades de saúde) foram liberadas/os da atuação presencial nos serviços e passaram a realizar integralmente as atividades específicas e relacionadas ao apoio ao combate à COVID-19 em domicílio. Para as/os profissionais de saúde que não atendiam aos critérios de teletrabalho integral, objetivando a liberação de espaço físico para atendimento separado de pessoas com e sem sintomas respiratórios e a redução do fluxo de circulação nos serviços de saúde, o sistema misto de trabalho também foi autorizado.

Desde então, as/os profissionais do NASF-AB realizam uma parcela importante de seus atendimentos à população e às eSF por meio de teleatendimento (SILVEIRA; ZONTA, 2020), seja a partir do domicílio ou institucionalmente, onde são realizadas teleorientação, teleconsulta e telemonitoramento. Os atendimentos por telemedicina na saúde pública em Florianópolis/SC, para algumas especialidades médicas, já eram incentivados antes da pandemia de COVID-19. Segundo Silveira e Zonta (2020), foi a introdução dessa modalidade de atendimento que possibilitou a rápida reorganização dos serviços, fornecendo respostas ágeis às demandas da pandemia.

No caso de uma parcela das/os Assistentes Sociais que atuam no NASF-AB, a pandemia de Covid-19 tornou o teletrabalho uma nova realidade, visando proteger a população atendida e as/os trabalhadoras/res que prestam os atendimentos. No entanto, esse teletrabalho se configurou como uma especificidade importante a ser analisada: o teletrabalho institucional, ou seja, o atendimento realizado por meio das TIC no ambiente da instituição empregadora. Essa organização do trabalho passou a ser desenvolvida principalmente pelas/os profissionais que não se enquadravam nos grupos de risco para COVID-19 e, por conta disso, não puderam se afastar totalmente das atividades presenciais.

Com a pandemia

[...] o que era uma tendência apontada por meio de experiência com projetos-piloto, seja no setor privado, seja no público, passou a ser implantada repentinamente para um conjunto de trabalhadores/as ao mesmo tempo. Sem debate entre os/as trabalhadores/as e organização coletiva, o teletrabalho se transforma subitamente em uma realidade. (CFESS, 2020, p. 5, grifos do autor).

A rapidez com que se fez necessária a reorganização dos serviços de saúde no início da pandemia dificultou a organização das/os profissionais. Durante todo o primeiro ano da pandemia (2020), o trabalho foi sendo realizado combinando momentos a distância com presenciais, em domicílio e na instituição, até que novas situações surgissem, como o início da vacinação, que rapidamente priorizou as/os trabalhadoras/es de saúde e o estabelecimento de regras para o teletrabalho. 
Em relação a essa última situação, a PMF, em fevereiro de 2021, publicou o Decreto n. 22.436, que regulamentou o trabalho não presencial no âmbito dos órgãos e das entidades da administração direta, autárquica e fundacional do poder executivo do município. Foi instituído o “teletrabalho e o home office como modalidades de serviço público não presencial, a ser executado por agentes públicos municipais, fora das dependências da repartição pública, de forma remota, por meio de equipamentos tecnológicos" (FLORIANÓPOLIS, 2021a, p. 1, grifo nosso).

A medida municipal via decreto substituiu a portaria publicada em abril de 2020, no início do período de emergência sanitária, que autorizava servidoras/es a desempenharem suas atividades em regime de teletrabalho durante o tempo necessário para garantir segurança sanitária em razão da pandemia causada pela COVID-19. A principal mudança observada é que se passa de uma medida excepcional, mesmo o período pandêmico não tendo se encerrado, para a instituição do teletrabalho como uma modalidade permanente na administração pública municipal.

o decreto define trabalho não presencial, home office e teletrabalho da seguinte forma:

I - Trabalho não presencial: modelo de trabalho realizado fora das dependências da instituição, de forma remota, em local adequado às condições de privacidade e segurança exigidas pelo serviço, à escolha do agente público, mediante a utilização de tecnologias de informação e de comunicação, com acesso ao sistema informatizado disponibilizado pelo Município, e é dividido em duas categorias que são o home office e o teletrabalho;

II - Home office: modalidade de trabalho não presencial no qual o agente público deve realizar as atividades repassadas pela chefia e a jornada de trabalho diária integral em horário pré-estabelecido pela Administração Pública, ficando à disposição do Município durante seu horário de expediente para, também, realizar o atendimento ao público interno e externo, por telefone ou por outro meio de comunicação;

III - Teletrabalho: modalidade de trabalho não presencial no qual devem ser cumpridas metas de produtividade, sem a fixação de horário específico para o desempenho das atividades; (FLORIANÓPOLIS, 2021a, p. 1-2).

As atividades desenvolvidas em teletrabalho e home office se equiparam àquelas exercidas de forma presencial, com a diferença que, remotamente, a/o servidor/a não poderá realizar hora extra e não receberá ajuda de custo, adicional noturno, hora plantão ou vale-transporte. No caso deste último benefício, ele será pago proporcional, quando a/o servidor/a realizar trabalho não presencial parcial, recebendo pelos dias trabalhados presencialmente (FLORIANÓPOLIS, 2021a).

O decreto, em suas disposições finais, incluiu no trabalho não presencial integral as/os servidoras/es que adoecerem ou tiverem suspeita DE COVID-19 e abre a mesma possibilidade para aqueles que pertencerem ao grupo de risco do novo coronavírus, com a opção de trabalho também em sistema de rodízio ou alternância de horários (FLORIANÓPOLIS, 2021a).

No entanto, os objetivos expressos com o trabalho não presencial indicam que não é somente a necessidade de proteção das/os trabalhadoras/es contra o contágio da COVID-19 que mobilizou a administração municipal a elaborar o Decreto n. 22.436/2021. Dentre os objetivos, destaca-se:

I - aumentar a produtividade e melhorar a qualidade dos serviços prestados pelos agentes públicos, com a correspondente economia na administração pública; II - promover a cultura orientada a resultados, com foco no incremento da eficiência e da efetividade dos serviços prestados à sociedade; III - atrair 
servidores qualificados, motivá-los e comprometê-los com os objetivos da instituição, de modo a reduzir afastamentos e desistências por falta de flexibilização quanto ao local, dias e horários da execução das atividades; IV - otimizar tempo e reduzir o custo de deslocamento dos agentes públicos até o local de trabalho, além de ampliar a possibilidade de trabalho aos agentes públicos com dificuldade de deslocamento, contribuindo com a mobilidade urbana; $\mathrm{V}$ - contribuir para a redução de custos e a melhoria dos resultados dos programas socioambientais, de poluentes, esgoto, consumo de água, energia elétrica, papel e outros bens e serviços disponibilizados no município de Florianópolis; [...]. (FLORIANÓPOLIS, 2021a, p. 2, grifo nosso).

Conforme expresso na Instrução Normativa n. 65/2020, publicada pelo Governo Federal e mencionada anteriormente, o município segue a mesma linha de racionalização dos custos operacionais, e ainda apela para a contribuição ambiental de que o trabalho não presencial provocaria (em razão do trânsito e mobilidade caótica da cidade), uma vez que diminuiria os deslocamentos e, consequentemente, os poluentes e o consumo de água, energia elétrica e papel. Não se desconsidera a importância de estabelecer processos de uso racional de bens naturais, no entanto, as justificativas para adoção do teletrabalho se fundamentam em bases questionáveis, quando se pensa no trabalho nos serviços sociais das políticas de saúde, assistência social e educação que dependem de suas/seus trabalhadoras/es atuando presencialmente.

A pretendida economia estatal está baseada na transferência e privatização dos custos do trabalho às/aos trabalhadoras/es. Como prevê o art. 22 da Instrução Normativa n. 002/SMA/2021: "É de inteira responsabilidade do agente público providenciar e manter, às suas expensas, as estruturas física e tecnológica necessárias à realização do trabalho não presencial, mediante o uso de equipamentos adequados e ergonômicos" (FLORIANÓPOLIS, 2021b, p. 7).

Nessa lógica, vale destacar que poucas/os profissionais vinculadas/os ao NASF-AB receberam um aparelho de telefone celular para o teleatendimento às/aos usuárias/os, além disso, a gestão municipal não disponibilizou chips com linhas telefônicas e internet. Ou seja, as/os profissionais precisaram comprar, com recursos próprios, esse insumo, ou articular com os Centros de Saúde para utilização de uma linha fixa para utilização do Whatsapp ${ }^{\circledR}$ nos aparelhos celulares. Nesse caso, a/o profissional precisou arcar com recursos, como internet, para realizar seu trabalho, assumindo a responsabilidade trazida pela Instrução Normativa n. 002/SMA/2021. Essa responsabilidade é assumida pela/o trabalhador/a em um termo de adesão e, além de não receber ajuda de custo para adequação e aquisição de bens e equipamentos necessários ao desenvolvimento do trabalho, ainda deve deixar o ambiente de trabalho não presencial adequado, pois está prevista uma vistoria ao local (FLORIANÓPOLIS, 2021b, p. 7).

O pano de fundo da adoção do trabalho não presencial esconde questões estruturais, como é o caso das más condições de trabalho oferecidas às/aos profissionais. Exemplo disso são as condições precárias de trabalho das/os profissionais do NASF-AB, que compreendem desde a falta de recursos humanos que atendam às necessidades dos serviços, passando pela inadequação das equipes às normativas federais, como é o caso da inclusão de um mesmo profissional em dois NASF-AB do município, e chegando até a ausência de espaços físicos, tecnologias e materiais necessários para a realização do trabalho de forma sigilosa. Ou seja, faltam salas para atendimento nos Centros de Saúde; telefone em local adequado e que permita o contato com a/o usuária/o ou rede de serviços com sigilo; computador com acesso à internet para os registros profissionais e consulta aos prontuários eletrônicos das/os usuárias/os, entre outras necessidades. 
Com o avanço da modalidade do teletrabalho será necessário que as/os Assistentes Sociais reflitam sobre as condições de trabalho e os custos gerados pelo "uso e aquisição de equipamentos, material de informática, conserto de equipamentos, rede de internet, material de consumo, energia e infraestrutura, entre outros" (CFESS, 2020, p. 5). Esses custos pesam para as/os profissionais atuantes na área da saúde em Florianópolis/SC, em razão disso, a realização do teletrabalho no âmbito institucional é uma possibilidade de continuar atendendo com qualidade às/aos usuárias/ os do SUS e fazer resistência à privatização do próprio espaço de trabalho.

Apesar de não haver "vedação normativa, a priori, ao teletrabalho" no Serviço Social, a atuação na área da saúde exige o contato com a realidade da população usuária do SUS e, no caso da APS, o trabalho possui como prerrogativa o conhecimento do território vivo. "O conhecimento gerado a partir das vivências profissionais é o que dá condições para a construção de respostas profissionais no âmbito do Serviço Social" (CFESS, 2020, p. 6).

A área estratégica do Serviço Social no NASF se constrói com base no território onde se encontram os indivíduos, suas famílias, a comunidade, os equipamentos sociais e as redes que o tornam um espaço vivo e dinâmico (MARTINI; DAL PRÁ, 2018). Por isso,

[...] a pandemia e a instituição do trabalho realizado por meios exclusivamente remotos limitam a realização de processos avaliativos e prejudicam a emissão de pareceres conclusivos, devendo os/as profissionais posicionar-se sobre as possibilidades e limites, de acordo com as condições de trabalho em relação à demanda. (CFESS, 2020, p. 13).

É pertinente, portanto, diferenciar o trabalho remoto do uso de ferramentas remotas, pois, como mencionado, algumas ferramentas remotas já eram utilizadas pelas/os profissionais de Serviço Social Florianópolis/SC antes da pandemia. Todavia, seja em um contexto de teletrabalho ou no trabalho presencial, "o uso das ferramentas remotas precisa ser avaliado em relação à finalidade do trabalho e aos limites relacionados às condições éticas e técnicas para sua execução" (CFESS, 2020, n.p.).

No caso de Florianópolis/SC, a mudança do sistema de prontuário eletrônico iniciada em 2019 já visava que a/o trabalhador/a o acessasse de sua residência ou de qualquer outro espaço que não fosse o das unidades de saúde. Sendo assim, sem sala e sem computador para atendimento, a alternativa será consultar os prontuários e realizar os registros profissionais no "conforto de casa".

O tema do acesso aos sistemas (o prontuário eletrônico da saúde sendo um desses) e softwares institucionais está previsto no Decreto n. 22.436/2021, que trata da disponibilização do acesso remoto e controlado aos trabalhadores em trabalho não presencial do município. De acordo com o decreto, haverá suporte "para a solução de problemas relacionados ao acesso e ao funcionamento dos sistemas institucionais, observado o horário de expediente”. Esse suporte, no entanto, não inclui manutenção em equipamentos pessoais de informática da/o trabalhador/a em trabalho não presencial (FLORIANÓPOLIS, 2021b, p. 7).

Além disso, é necessário salientar que o acesso das/os usuárias/os às TIC não é amplo e disseminado, havendo muitas dificuldades enfrentadas pela população no uso da tecnologia, que vão desde o não acesso ao celular, à internet e a aplicativos de mensagens, até limitações por questões relacionadas à escolaridade, no caso de usuárias/os analfabetas/os ou semianalfabetas/ os e à compreensão das ferramentas e sistemas utilizados pelos diferentes serviços sociais. 
A desigualdade no acesso tecnológico foi evidenciada com a informatização de muitos dos serviços sociais, que passaram a operar intensivamente por meio de TIC como: e-mail, telefone, mídias sociais (Facebook ${ }^{\circledast}$, Instagram ${ }^{\circledR}$ ) e aplicativos de mensagens (Whatsapp ${ }^{\circledR}$ ) e de serviços (Meu INSS, Caixa Econômica Federal etc.). Na área da previdência social, as/os profissionais passaram a centrar suas orientações às/aos usuárias/os e às eSF para viabilizar o acesso informatizado à direitos sociais básicos, como perícias médicas e auxílio-doença, uma vez que as agências do Instituto Nacional do Seguro Social (INSS) fecharam por um longo período e os atendimentos passaram a ser realizados pelo site ou pelo aplicativo Meu INSS.

$\mathrm{Na}$ área da assistência social, as orientações profissionais tiveram como enfoque o acesso por telefone, Whatsapp ${ }^{\circledR}$, e-mail e Facebook ${ }^{\circledR}$ aos Centros de Referência da Assistência Social (CRAS) e demais serviços da política que, no período inicial da pandemia, suspenderam os atendimentos presenciais. As/os Assistentes Sociais do NASF-AB produziram inúmeros materiais informativos (sobre os direitos, os benefícios e os auxílios sociais existentes e aqueles que passaram a ser ofertados) durante a pandemia para serem divulgados nas mídias sociais e Whatsapp ${ }^{\circledR}$, visando o acesso da população. Destaca-se que a maior demanda de orientações ocorreu em função do auxílio emergencial - benefício financeiro concedido pelo Governo Federal no ano de 2020 com o objetivo de fornecer proteção emergencial no enfrentamento à crise causada pela pandemia de COVID-19.

Essas demandas profissionais indicam a necessidade de debate sobre o trabalho mediado pelas ferramentas remotas. A tecnologia não pode ser utilizada como único instrumento de trabalho, já que

[...] o conhecimento sobre as condições de vida e trabalho e da forma de acesso, ou não, da população aos direitos e políticas sociais é aspecto central do trabalho de Assistentes Sociais e tem, no trabalho coletivo, no diálogo e atendimento presencial, um lócus privilegiado. Porque o trabalho de Assistentes Sociais não se limita à orientação procedimental para acesso a direitos e políticas sociais, mas envolve práticas educativas e reflexivas acerca da importância da organização política no contexto das relações sociais de produção e reprodução social. (CFESS, 2020, n.p.).

No entanto, o horizonte das mudanças trabalhistas indica que o teletrabalho será uma condição imposta às/aos trabalhadoras/es dos serviços sociais públicos. Como sujeitos da classe trabalhadora, estamos vivendo "[...] o momento da quarta revolução industrial”, onde tudo é digitalizado, tudo está conectado, e digitalizando tudo que se pode digitalizar, cria-se "uma massa limitada de empregos mais qualificados", que gera, portanto, "uma massa imensa de desempregados que não têm condições de suprir esses empregos qualificados que são reduzidos" (ANTUNES, 2018, n.p.). Ainda segundo Antunes (2018, n.p.), “[...] a indústria 4.0 vai dispensar a força de trabalho e com isso tornar mais lucrativa a produção”. Então, para onde e como se deve caminhar no sentido de minimizar os impactos das TIC na vida das/os trabalhadoras/es?

Como consequência das novas formas de contratação pelo ambiente digital, em um mundo digitalizado, tem-se a informalização, a flexibilização das legislações trabalhistas e a precarização do trabalho. Exigências de um mundo sob o comando do capital financeiro, onde a lógica é gerar mais dinheiro, não importa como. Desse modo, explorar a classe trabalhadora, em todas as suas dimensões, em todos os seus momentos, em todos os seus segundos, é o principal objetivo deste modelo instaurado mundialmente. Para isso, destrói-se a legislação social, protetora do trabalho 
e tão duramente conquistada, e abre-se precedente para o trabalho terceirizado - como uma forma de escravidão (ANTUNES, 2018).

Será preciso pensar em saídas e proposições realmente sólidas, a fim de responder às demandas de médio e longo prazo relacionadas às mudanças no trabalho. Nas políticas de assistência social e saúde, coloca-se como principal questão assegurar condições de trabalho diante da precariedade, da ausência de Equipamentos de Proteção Individual (EPI), da intensificação das demandas e da fragilidade dos vínculos de trabalho decorrentes das contratações temporárias e urgentes.

\section{Considerações finais}

A pandemia de COVID-19 trouxe inúmeros desafios para os setores públicos e privados, sendo que a divisão dos serviços em essenciais e não essenciais colocou em voga a necessidade de reorganização da atuação profissional, visando miminizar os riscos de contaminação pelo novo coronavírus.

Para as/os Assistentes Sociais da área da saúde não foi diferente, por não estarem na linha de frente do atendimento às/aos usuárias/os com sintomas respiratórios, precisaram reorganizar sua intervenção profissional e, para isso, utilizarem-se das TIC e do teletrabalho, a fim de continuar desenvolvendo o atendimento à população. No município de Florianópolis/SC, muitas/os profissionais passaram a realizar seu trabalho de forma remota ou mista, e mesmo aqueles as/ os que permaneceram atuando presencialmente nos locais de trabalho precisaram ampliar o uso de TIC para o contato com a população e com as eSF.

O uso das TIC não foi uma novidade imposta pela pandemia no município, pois muitas eSF e profissionais do NASF-AB, entre elas/es as/os Assistentes Sociais, já utilizavam essas ferramentas para desenvolver suas atividades, principalmente relacionadas ao apoio técnico pedagógico entre as/os profissionais, sendo apenas ampliado o uso para o atendimento às/aos usuárias/os.

Deve-se destacar, porém, que essa ampliação trouxe inúmeros desafios, sejam eles relacionados ao acesso das/os usuárias/os aos sistemas, aplicativos e redes utilizadas pelos serviços, sejam para a/o própria/o profissional, visto que as instituições passaram às/aos trabalhadoras/ es a responsabilidade pelos meios e condições de trabalho. Ou seja, a escolha de ambientes adequados e ergonômicos, nem sempre adequados na residência das/os trabalhadoras/es; e a aquisição e manutenção dos equipamentos para o teletrabalho, como aparelhos telefônicos, chips e computadores, passou a ser exclusivamente de responsabilidade das/os profissionais.

A pandemia “tem possibilitado um verdadeiro 'laboratório' de experiências, tanto na esfera pública quanto na privada, resultando em maior exploração da força de trabalho e diminuição dos seus custos" (TEJADAS; JUNQUEIRA, 2021, p. 110).

A necessidade das instituições de continuarem ofertando seus serviços, aliada à redução de custos que o teletrabalho proporcionou, ampliou significativamente a precarização do trabalho e a sobrecarga das/os profissionais, que precisaram aliar o trabalho com a vida pessoal, principalmente para quem precisou se afastar do trabalho presencial.

Apesar de que, com o avanço da vacinação da COVID-19, grande parte das/os profissionais da saúde já puderam retornar ao trabalho presencial, o teletrabalho institucional ainda é uma realidade presente no dia a dia dos/as profissionais da saúde, dentre elas/es as/os Assistentes Sociais e, possivelmente, uma realidade que, se não for barrada pelos Conselhos Profissionais, 
continuará existindo mesmo após a pandemia e cada vez mais será considerado um pandemônio para as/os profissionais e usuárias/os.

É importante mencionar que o uso das TIC para qualificar os atendimentos e a atuação profissional é considerado um avanço, mas quando subsidiado de forma adequada pelas instituições e serviços, ou seja, quando todos os meios e instrumentos de trabalho são disponibilizados e mantidos pelas instituições e serviços, sem ônus às/aos trabalhadoras/es, porém, na medida em que essa responsabilidade é repassada às/aos profissionais, o uso de TIC torna-se mais uma forma de precarização e privatização do trabalho e do acesso às/aos usuárias/os aos serviços de saúde e das outras políticas sociais.

Ainda há muito por avançar na discussão acerca das TIC e do teletrabalho, e ainda mais na construção de relações de trabalho que sejam benéficas, saudáveis e justas para os serviços e instituições, mas principalmente para as/os trabalhadoras/es e usuárias/os dos serviços de saúde, serviço desde sempre considerado essencial para a manutenção da vida.

\section{Referências}

ANTUNES, Ricardo. Digitalização do trabalho e a escravidão no século 21. Extra Classe. 26 jul. 2018. Entrevista para Marcelo Menna Barreto. Disponível em: https://www.extraclasse.org.br/ geral/2018/07/digitalizacao-do-trabalho-e-a-escravidao-no-seculo-21/. Acesso em: 5 nov. 2020.

BARROS, Alexandre Moço; SILVA, José Roberto Gomes. Percepções dos indivíduos sobre as consequências do teletrabalho na configuração home-office: estudo de caso na Shell Brasil. Cadernos EBAPE. BR, v. 8, n. 1, Rio de Janeiro, p. 73-91, 2010. Disponível em: https://www.scielo.br/pdf/cebape/ v8n1/a05v8n1.pdf. Acesso em: 3 maio 2021.

BRASIL. Instrução Normativa n. 65, de 30 de julho de 2020. Estabelece orientações, critérios e procedimentos gerais a serem observados pelos órgãos e entidades integrantes do Sistema de Pessoal Civil da Administração Federal - SIPEC relativos à implementação de Programa de Gestão. Diário Oficial da União: seção 1, Brasília, DF, edição 146, p. 21, 31 jul. 2020. Disponível em: https://www. in.gov.br/en/web/dou/-/instrucao-normativa-n-65-de-30-de-julho-de-2020-269669395. Acesso em: 5 maio 2021.

BRASIL. Lei n. 13.467, de 13 de julho de 2017. Altera a Consolidação das Leis do Trabalho (CLT), aprovada pelo Decreto-Lei n. 5.452, de $1^{\circ}$ de maio de 1943, e as Leis n. 6.019, de 3 de janeiro de 1974, 8.036, de 11 de maio de 1990, e 8.212, de 24 de julho de 1991, a fim de adequar a legislação às novas relaç̃oes de trabalho. Diário Oficial da União: seção 1, Brasília, DF, edição 134, p. 1, 14 jul. 2017. Disponível em: encurtador.com.br/bsuP7. Acesso em: 7 abr. 2021.

BRASIL. Lei n. 12.551, de 15 de dezembro de 2011. Altera o art. $6^{\circ}$ da Consolidação das Leis do Trabalho (CLT), aprovada pelo Decreto-Lei n. 5.452, de 1 de maio de 1943, para equiparar os efeitos jurídicos da subordinação exercida por meios telemáticos e informatizados à exercida por meios pessoais e diretos. Diário Oficial da União: seção 1, Brasília, DF, edição 134, p. 3, 16 dez. 2011. Disponível em: http:// www.planalto.gov.br/ccivil_03/_ato2011-2014/2011/lei/112551.htm. Acesso em: 28 abr. 2021.

BRASIL. Decreto-Lei n. 5.452, de 1º de maio de 1943. Aprova a Consolidação das Leis do Trabalho. Diário Oficial da União: seção 1, Rio de Janeiro, RJ, p. 11937, 9 ago. 1943. Disponível em: http://www.planalto. gov.br/ccivil_03/decreto-lei/del5452.htm. Acesso em: 7 abr. 2021. 
BRIDI, Maria Aparecida et al. O trabalho remoto/home-office no contexto da pandemia COVID-19. REMIR Trabalho, 24 jul. 2020. Disponível em: https://www.eco.unicamp.br/remir/images/ Artigos_2020/ARTIGO_REMIR.pdf. Acesso em: 10 maio 2021.

CFESS. Conselho Federal de Serviço Social. Teletrabalho e teleperícia: orientações para assistentes sociais. Brasília, DF: CEFESS, 2020. Disponível em: http://www.cfess.org.br/arquivos/teletrabalhotelepericia2020-nota.pdf. Acesso em: 13 ago. 2020.

FÁVERO, Eunice. Introdução: aproximações ao contexto da pandemia, da realidade social e do exercício profissional da/o assistente social. In: NCA-SGD. Núcleo de Estudos e Pesquisas sobre crianças e Adolescentes - ênfase no Sistema de Garantia de Direitos. 0 exercício profissional da/o assistente social em espaços sócio-ocupacionais do sociojurídico no contexto da pandemia e do teletrabalho: contribuições ao debate. São Paulo: NCA-SGD, maio 2020. Boletim n. 1. p. 3-14. Disponível em: encurtador.com.br/vBFT1. Acesso em: 22 set. 2021.

FILHO, José Sarto Fulgêncio de Lima; BRASIL, Ana Larissa da Silva. O conceito legal de teletrabalho e suas repercussões nos direitos do empregado. Revista Juris UniToledo, Araçatuba, SP, v. 4, n. 1, p. 111126, 2019. Disponível em: encurtador.com.br/vyDN6. Acesso em: 7 abr. 2021.

FLORIANÓPOLIS. Decreto n. 22.436, de 05 de fevereiro de 2021. Regulamenta o trabalho não presencial no âmbito dos órgãos e das entidades da administração direta, autárquica e fundacional do Poder Executivo do Município de Florianópolis. Diário Oficial Eletrônico do Município de Florianópolis: edição n. 2878, Florianópolis, SC, p. 1-3, 8 fev. 2021a. Disponível em: http://www.pmf.sc.gov.br/ arquivos/diario/pdf/08_02_2021_20.32.17.73286a6a4fe74d7935e8d1bb0882ccfc.pdf. Acesso em: 12 maio 2021.

FLORIANÓPOLIS. Instrução Normativa n. 002/SMA/2021b. Institui o Comitê Gestor do Home Office e Teletrabalho (CGHOT) e dispõe acerca da aplicação e aferição da realização de atividades laborais fora das dependências das entidades da administração direta, autárquica e fundacional do Poder Executivo do Município de Florianópolis. Diário Oficial Eletrônico do Município de Florianópolis: edição n. 2878, Florianópolis, SC, p. 13 (anexo), 8 fev. 2021b. Disponível em: http://www.pmf.sc.gov.br/arquivos/ diario/pdf/08_02_2021_20.32.17.73286a6a4fe74d7935e8d1bb0882ccfc.pdf. Acesso em: 12 maio 2021.

FLORIANÓPOLIS. Secretaria Municipal de Saúde. Guia de orientações para o enfrentamento da pandemia de COVID-19. Orientações voltadas à rede de Atenção Primária à Saúde (APS) de Florianópolis/SC. Florianópolis: Secretaria Municipal de Saúde, 15 mar. 2020. Disponível em: https:// coremu.paginas.ufsc.br/files/2020/03/GUIA-DE-ORIENTAC\%CC\%A70\%CC\%83ES_APS_versa\%CC\%83o2_15mar2020.pdf . Acesso em: 13 maio 2020.

FLORIANÓPOLIS. Secretaria Municipal de Saúde. Portaria n. 22/2016 de 09 de novembro de 2016. Aprova a Política Municipal de Atenção Primária à Saúde para organização dos serviços e gestão e direcionamento das ações de educação permanente no âmbito da Atenção Primária à Saúde no município de Florianópolis. Diário Oficial Eletrônico do Município de Florianópolis: edição n. 1820, Florianópolis, SC, p. 15 (anexo), 9 nov. 2016. Disponível em: http://www.pmf.sc.gov.br/arquivos/arquiv on.p.df/29_11_2016_16.17.33.73c009e15b1538cd39469d1b7ec80eb2.pdf. Acesso em: 16 maio 2021.

FLORIANÓPOLIS. Secretaria Municipal de Saúde. Carteira de Serviços Atenção Primária em Saúde. Versão 1. Florianópolis: Secretaria Municipal de Saúde, 2014. Disponível em: encurtador.com.br/ciCM8. Acesso em: 16 maio 2021.

MARTINI, Débora; DAL PRÁ, Keli Regina. A inserção do assistente social na atenção primária à saúde. Argumentum, Vitória, v. 10, n. 1, p. 118-132, 2018. Disponível em: https://periodicos.ufes.br/ argumentum/article/view/18648/13184. Acesso em: 20 maio 2021. 
OIT. Organización Internacional del Trabajo. Convenio sobre el trabajo a domicilio. Ginebra: OIT, 20 jun. 1996. Disponível em: http://www.ilo.org/dyn/normlex/es/f?p=NORMLEXPUB:12100:0::NO: :P12100_INSTRUMENT_ID:312322. Acesso em: 25 mar. 2018.

ROCHA, Cháris Telles Martins da; AMADOR, Fernanda Spanier. O teletrabalho: conceituação e questões para análise. Cadernos EBAPE.BR, Rio de Janeiro, v. 16, n. 1, p.152-162, jan./mar. 2018. Disponível em: https://www.scielo.br/j/cebape/a/xdbDYsyFztnLT5CVwpxGm3g/?format=pdf\&lang=pt. Acesso em: 24 maio 2021.

SILVEIRA, João Paulo Mello; ZONTA, Ronaldo. Experiência de reorganização da APS para o enfrentamento da COVID-19 em Florianópolis. APS em Revista, Belo Horizonte, v. 2, n. 2, p. 91-96, jun. 2020. Disponível em: https://apsemrevista.org/aps/article/view/122/57. Acesso em: 23 jul. 2020.

SOUZA, Thaís Titon; MARTINI, Débora. Monitoramento e avaliação como ferramentas de gestão do processo de trabalho integrado entre Núcleos de Apoio à Saúde da Família e equipes de Saúde da Família. Revista de Saúde Pública de Florianópolis, Florianópolis, ano 2, n. 2, p.15-19, dez. 2014. Disponível em: https://issuu.com/revistasaudepublicafpolis/docs/rspf_a2n2_ebook_2e392af6c72fd3. Acesso em: 17 maio 2020.

TEJADAS, Silvia da Silva; JUNQUEIRA, Maíz Ramos. Serviço Social e pandemia: desafios e perspectivas para a atuação no sociojurídico. Serviço Social \& Sociedade, São Paulo, n. 140, p. 101-117, jan./abr. 2021. Disponível em: https://www.scielo.br/j/sssoc/a/Jq7JHTH5Ts7LDQZVLRfBTHp/?format=pdf\&lang =pt. Acesso em: 20 maio 2021. 